\title{
Analysis of the legislation of the Russian Federation in the field of organic agriculture
}

\author{
Tatyana Agafonova ${ }^{1 *}$ \\ ${ }^{1}$ Institute of Service and Entrepreneurship (branch) of DSTU, 147 Shevchenko str., Shakhty, Rostov \\ region, 346500, Russia
}

\begin{abstract}
At present organic agriculture is one of the key areas of economic development in the Russian Federation. The article examines the issues of the current state of organic agriculture and its regulatory and legal regulation in the Russian Federation. The study is based on the analysis of the law "On Organic products and amendments to Certain Legislative Acts of the Russian Federation" adopted on July 25, 2018. In the course of the work, trends and main provisions concerning organic agriculture were identified, as well as problems and prospects for improving legal regulation in the field under study were identified.
\end{abstract}

\section{Introduction}

Recently, organic agriculture has been gaining momentum in the development of the agroindustrial complex. This is due to the high rate of development of this industry and the release of new laws that control this area. The main purpose of the study is to study the problem of legal regulation of organic agriculture. The subject of the study is to improve the quality of products produced in the Russian Federation on the world market and to consider the legislation regulating organic agriculture.

\section{Methodology}

In the research the author analyzes the normative legal acts and draft laws regulating organic agriculture in the agro-industrial complex of our country.

\section{Results of the research}

Farming is a critical and essential food-production process for humanity. The world's population will grow to 9.1 billion to the year 2050. The agricultural-sector should increase food production by $70 \%$ to nourish the world's population. This increase should consist of 3 billion tonnes of grain and 0.47 billion tonnes of meat. The farming changes should include the use of chemical fertilisers to accelerate growth. For this reason more than 5 million

\footnotetext{
*Corresponding author: A89518438682@yandex.ru
} 
tonnes of agricultural chemicals will be used annually by the year 2000 . Therefore, the large annual use of pesticides will accumulate and contaminate the ecosystem.

The effects of agricultural chemical contamination in the air, water, and soil profoundly affect human health through the accumulation of toxins from living in an environment full of toxins and the consumption of toxic food. This effect should increase the rates of asthma, autism, physical disabilities, learning disabilities, reproductive disorders, diabetes, Parkinson disease, Alzheimer disease and cancer. In addition to directly affecting human health, chemicals from agricultural activities also affect the ecosystems of plants and animals. Finally, humans are affected by the consumption of these products and meat. The use of chemical fertilisers, insecticides, and pesticides has continued for a long time in the agricultural production process and is widely found in farm systems and small farms, where the health effects are found both in consumers and farmers who use chemicals for agricultural activities.

Consequently, avoiding the use of chemicals by substituting current practices with organic farming is an appropriate solution to these human and environmental problems. The consumption of organic products is increasing because of the awareness of the dangers of contaminated foodstuffs. Organic food is gaining popularity among consumers who love the earth and want to care for their health. [1].

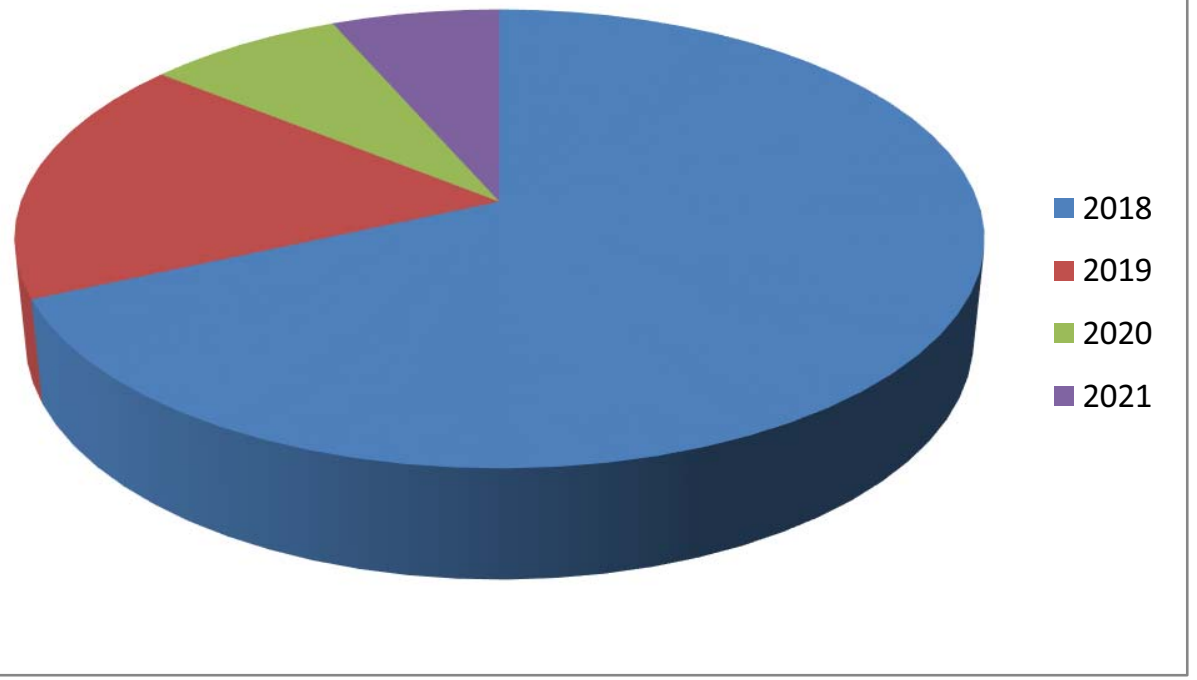

Fig. 1. The global market for organic products.

Under the term organic agriculture or organic farming and animal husbandry, it is customary to understand such methods of obtaining agricultural products, in which the use of artificial (synthetic) preparations - fertilizers, pesticides, growth stimulants, feed additives, and others-is purposefully minimized.

Organic agriculture is often proposed as a solution for producing food with reduced environmental impact (Tilman, 1998, Scialabba, 2002). Even though it constitutes less than $1 \%$ of global agricultural land and less than $5 \%$ of retail sales in most high-income countries (Willer and Lernoud, 2015), it represents one of the fastest growing food sectors. In high-income countries most people consume organic at least occasionally.1 Organic today is the most recognized food label, whose basic meaning is understood by most consumers. And organic is the only farming system whose management practices are codified by law in most countries (Rigby and Cáceres, 2001) [7]. Organic food thus 
represents one of the few means through which consumers can have some control and knowledge about how their food is produced (Allen and Kovach, 2000).

But what does organic agriculture actually mean? The meaning of organic is shaped by the different actors involved - consumers, producers, theoreticians, and regulations (see Fig. 1). Accordingly, there have been many debates about the definition of organic agriculture (Rigby and Cáceres, 2001), as well as the different forms in which it manifests itself today (Guthman, 2004). Many of the commonly cited definitions are ambiguous (e.g. IFOAM, 2006), and different people associate different things with it and buy organic for different reasons (Hughner et al., 2007). This wealth of meanings and associations is also rooted in the history of organic agriculture and in the manifold ideas expressed by the original organic movement (Conford, 2001, Heckman, 2006). But the lack of a clear vocabulary and conceptualization of organic agriculture makes a discussion about its problems and benefits challenging. Indeed, debates about whether organic farming could contribute to more sustainable agriculture are often highly polarized (Trewavas, 2001, Goklany, 2002, Mäder et al., 2002) [8].

Organic farming for higher ecological and human health benefits has been adopted in about 186 countries, covering a total area of 71.5 Mha worldwide. Because of the associated practices, the flows of several environmental pollutants into the organic products threaten food safety and human health. The contaminants that occur at higher concentrations in organic produce include persistent organic pollutants $(61.3-436.9 \mathrm{ng} \mathrm{g}-1$ lamb meat, and $0.28 \mathrm{pg} \mathrm{g}-1-2.75 \mathrm{ng} \mathrm{g}-1$ bovine meat), heavy metals $(0.5-33.0 \mathrm{mg} \mathrm{kg}-1$ lettuce), organochlorine pesticides (11-199 $\mu \mathrm{g} \quad \mathrm{g}-1$ carrots), cyclodienes, hexachlorocyclohexanes, hexabromocyclododecane (2-3 times higher than in conventionally produced porcine meat), hexachlorobenzene (1.38-14.49 $\mathrm{ng} \mathrm{g}-1$ fat in milk), and non-brominated flame retardants (1.3-3.2 times higher than in conventional produce of greenhouse-grown tomato and cucumber). Moreover, some pollutants like perand polyfluoroalkyl substances with a longer half-life (1.50-9.10 yrs) are reported to occur in several organic products. In fact, several legacy persistent organic pollutants are known for their significant trophic magnification in an urban terrestrial ecosystem. In addition, many plant functionalities are adversely affected in organic farming. Therefore, the longterm usage of organic products containing such pollutants poses a significant threat to human health. The major limitation in organic livestock production is the severe shortage of organic feed. Several variable standards and technical regulations set by the government and private agencies are the major obstacles in the global marketing of organic products [9].

Organic agriculture is a production system that aims to maintain the health of the soil, ecosystems, and people.Organic agriculture, also known as biological or ecological agriculture, combines traditional conservation-minded farming methods with modern farming technologies. It emphasizes rotating crops, managing pests naturally (without special intervention in a natural manner), diversifying crops and livestock, and improving the soil with compost additions and animal and green manures. Many organic farmers use modern equipment, improved crop varieties, soil and water conservation practices, and the latest innovations in feeding and handling livestock. About $38 \%$ of the Earth's land cover is occupied by agriculture and $1 \%$ of these lands are now used in organic agriculture. Although agriculture provides growing supplies of food and other products, it is a major contributor to greenhouse gases, biodiversity loss, agrochemical pollution, and soil degradation. Although organic systems may yield less food, they can be more profitable, environmentally friendly, and deliver foods that contain less (or no) pesticide residues compared with conventional systems. Improvements to management techniques and crop varieties could close the yield gap between organic and conventional systems in spite of the significant barriers to adopting these systems. For example, conventional farming uses chemical fertilizers to promote plant growth, whereas organic farming employs manure and 
compost to fertilize the soil. Organic farmers turn to insects and birds, mating disruption, or traps, whereas conventional farming sprays pesticides to get rid of pests. Conventional farming uses chemical herbicides to manage weeds, whereas organic farming rotates crops, hand weeds, or mulches.

Currently, the market of organic farming in the Russian Federation is just beginning its formation and development, but despite this, it can already be called highly promising. This is due to the fact that the main factor hindering the development of organic agriculture in developing countries is the lack of the necessary amount of land resources, and on the territory of the Russian Federation there are about 20 million hectares of land that have not been treated with chemicals for more than 3 years, which means that they are suitable for organic farming.In the annual Address of the President of the Russian Federation to the Federal Assembly on December 3, 2015, in particular, it was emphasized that Russia is able to become the world's largest supplier of healthy, environmentally friendly, high-quality food products, which have long been lost from some Western manufacturers, especially since the demand on the global market for such products is steadily growing [2]. According to a study conducted by the Union of Organic Agriculture in 2018, the market for organic products in Russia was 120 million rubles. including imported organic products, $0.12 \%$ of agricultural land (246 thousand hectares) is certified as organic according to international standards. In total, there are 70 certified organic agricultural producers in Russia [10].

Of these, in the field of crop production - 20 farms, animal husbandry-5 farms, wild plants-14 farms, the production of alcoholic beverages-1 enterprise, processing-2 enterprises [3]. The main problems of the development of the organic products market in the Russian Federation are:

1. An unformed regulatory framework and regulatory system in the field of organic agriculture that corresponds to the current state of the industry, as well as a system of state support and an accessible conceptual framework;

2. Low demand for organic products, due to high margins, distrust of the domestic producer, the high risk of buying counterfeit products and the insufficient level of development of the ecological culture of the population;

3. The lack of harmonization of Russian standards for organic products with the standards of other countries, as well as an established system, channels and markets in the domestic market; To solve the above problems, first of all, it is necessary to create a fullfledged legal field in Russia that will regulate the functioning of the organic products market. Its absence currently does not allow Russia to act as a full-fledged participant in the international market, and within the countrycreates the possibility of selling a large number of counterfeit products with the signs "organic", "ecological" and "biological".

The adoption of the Federal Law "On the Quality and Safety of Food Products"on January 2, 2000 is considered to be the beginning of the formation of the regulatory framework in the organic industry in the Russian Federation. According to which, in the manufacture of children's and dietary food products, it is not allowed to use food raw materials made with the use of feed additives, animal growth stimulators, certain types of medicines, pesticides, agrochemicals and other substances and compounds dangerous to human health. On January 30, 2010, Decree N 120 of the President of the Russian Federation adopted the Food Security Doctrine, in which food security is declared one of the key areas of ensuring the country's security, a factor in preserving its statehood and sovereignty, and a necessary condition for the implementation of the strategic national priority - improving the quality of life of Russian citizens by guaranteeing high standards of life support. One of the most effective tools for solving these tasks is to provide the population with high-quality, safe and healthy products, which is implemented, including through organic agriculture [4]. 
Currently, the activities for the production and sale of organic products are regulated by three national standards: GOST R 56104-2014 " Organic food products. Terms and definitions", GOST R 56508-2015 " Organic production. Rules of production, storage, transportation" and GOST R 57022-2016 " Organic products. The procedure for conducting voluntary certification of organic production". In January 2018, the interstate standard (GOST 33980-2016/CAC/GL 32 - 1999, NEQ) came into force.

This standard regulates organic production in the CIS countries and provides a consistent approach to the requirements governing the production of organic products, their labeling and related product information. At the moment, the standard is valid on the territory of only three states - Russia, Kyrgyzstan and Tajikistan. Also in three regions of Russia, namely in the Ulyanovsk and Voronezh regions, and in the Krasnodar Territory, regional laws on organic agriculture have been adopted. In 2012, the first version of the Law "On the Production of Environmentally Friendly (organic) agricultural products and Amendments to Legislative Acts of the Russian Federation", prepared by the Ministry of Agriculture of the Russian Federation, was published, after which this document was finalized and the second version of the bill was published on July 17, 2013.

However, the bill was not approved, as it had the following significant drawbacks both from the point of view of Russian organic producers and from the point of view of the authorities. In particular, there were no criteria for identifying products as "organic" and clear, open and understandable information about passing the certification procedure, as well as no distinctive features for the processes of "organic production"[12]. The draft law did not comply with international standards of organic farming, which ensured the isolation of Russian agricultural producers, the lack of access to the international market and the realization of their competitive advantage. In addition, it was supposed to consolidate sole control over the Federal Executive Body, but at that time any state body lacked the necessary number of competent specialists, and the prescribed system of penalties to combat non-certified products was not effective, since it provided for fairly low fines. All the above shortcomings can be explained by the fact that despite the stated participation of business representatives from the field of organic agriculture in the development of the draft law, the draft did not pass coordination with the professional community and industry unions and associations, so the text of the document lacked a relationship with the real state of affairs in organic agriculture and provided for too strict control by the authorities, which created huge opportunities for corruption in this industry [11].

\section{Discussion of results}

The third version of the draft law "On the production of organic products" was developed by the Ministry of Agriculture of the Russian Federation together with specialists of the National Organic Union and presented to the government commission on legislative activities in December 2017. On January 18, 2018, the project was approved by the Federation Council of the Russian Federation and submitted to the State Duma for consideration. The purpose of the draft law is to develop the domestic market of organic products, meet the needs of the population of the Russian Federation in organic products, develop competition in the production and turnover of organic products, and increase its exports [5]. The draft law provides for the consolidation of the main terms and concepts, the differentiation of the main powers of state authorities and local self-government, the introduction of a unified state register of organic producers, the procedure for confirming the conformity of organic production, the requirements for labeling organic products, the introduction of state support, as well as information and methodological support for organic producers. After all three readings and the corresponding amendments, on July 25, 2018, the State Duma finally adopted the law "On Organic Products and Amendments to Certain 
Legislative Acts of the Russian Federation". The document was signed by the President of the Russian Federation on August 3, 2018.

The positive aspects also include the creation of a single open register of organic producers and the fact that only those certification bodies that will be accredited by the Federal Accreditation Service will be able to certify compliance with the national standard.

This circumstance will help to increase the competence of certification bodies, as well as to ensure an objective and complete verification of the manufacturer's compliance with the national standard. The adopted federal law is a framework law. It contains references to national, interstate and international standards, which allows for further work on their improvement and refinement. The law also provides for a transition period, during which the implementation of the rules of organic agriculture and organic production will be ensured and it will be prohibited to place officially accepted labeling on organic goods. In addition to the adoption of the law "On organic products" were also made positive changes to the Federal law "On state regulation of trade activities in the Russian Federation", which include a ban of the return distribution network business entity who carries out the supply of agricultural commodities such products, the shelf life is more than thirty days, except if the return of such goods is permitted or provided for in the legislation of the Russian Federation [13].

This phenomenon contributes to the strengthening of the competitiveness of Russian agricultural enterprises, since this measure was introduced for imported products for a long time before. Thus, the adoption of this law will have a positive impact not only for existing producers in the field of organic products, but also for the development of the entire industry as a whole, because according to information received from major experts of the German foreign audit company ABCERT, which inspects Russian farms wishing to pass certification according to European standards, since the beginning of the discussion of the draft law, there has been a steady increase in requests for information about the transition to organic agriculture by enterprises from different regions, some of them have already signed contracts for certification [6].

However, despite all the advantages mentioned above, this federal law, according to experts from the field of organic science, has a number of significant shortcomings and shortcomings.

First, the law is focused only on the regulation of the internal organic market, since the text of the document does not contain prerequisites for the harmonization of domestic and international standards, as well as the procedure for their recognition by each other. Currently, the Russian organic market produces mainly raw materialst.

Secondly, the adoption of this law, although it creates new opportunities and conditions in this industry, does not stimulate the growth of the number of organic farms, since the creation of legal regulation alone is not enough. Economic and informational support of the industry from the state is necessary. Small agricultural enterprises currently lack sufficient financial resources to restructure their operations and switch to organic farming. In this regard, it is necessary to pay attention to international practice, where part of the risks associated with the reimbursement of certification costs, the costs associated with crop failure, as well as the costs of the transition period, which is 24 months, is borne by the state. It is necessary to consider these mechanisms and develop similar or similar measures for Russian enterprises engaged in organic agriculture [14].

Third, it is necessary to start working on the development of channels and markets for organic products. Currently, producers of organic products, with the exception of enterprises located in the regions of the federal districts, are not interested in selling their goods on the domestic market for a number of reasons. First, the specifics of the production and sale of goods imply a higher price [15]. 
The cost price, in comparison with the goods of traditional agriculture, and in the conditions of unformed demand and lack of consumer confidence in this industry, sales at higher prices do not bring economic profit to enterprises.

Secondly, in the absence of established channels and markets, small agricultural enterprises do not have the opportunity to transport their own products from their regions to large cities and retail chains, so it is necessary to work on the construction and development of competent and efficient logistics chains between agricultural producers and specialized stores. Thus, summing up all of the above, it is necessary to emphasize once again that the organic agriculture industry currently has great prospects not only in the international market, but also in the domestic market of the Russian Federation. The development of organic products has a number of strategic economic, social and environmental advantages for Russia. In particular: Improving the level and quality of life of the population and, as a result, reducing social tension in rural and peripheral territories;

Reducing the outflow of population from rural areas and stimulating the migration of professional specialists to rural areas;

Increasing the nutritional value of food, improving the quality of nutrition of the population and reducing diseases of citizens of the Russian Federation. For the further development of organic agriculture, enterprises need not only a competent legal framework, but also knowledge, investment, stable demand and developed infrastructure. The organic industry today is closed and poorly understood by both potential participants and investors.

\section{Conclusions}

Organic regulations appear to be caught between different and often opposing interests and therefore watered-down to be rather one-dimensional. As the organic market continues to grow, and as more farmers enter organic production, and a larger, and more diverse group of consumers demands affordable chemical-free food, there is a risk that organic agriculture will be reduced even more to the lowest common denominator between the different interest groups, i.e. absence of synthetic substances. The original idea of organic being environmentally friendly farming is in danger of being lost.

Organic regulations are the place where organic agriculture is defined today. Organic regulations should therefore be very clear about what the goal of organic agriculture is. If organic agriculture is to primarily deliver chemical-free food to consumers, organic regulations should include more product standards (e.g. food safety, residue-free food) rather than prescribing process standards, as they do today. If organic agriculture is, instead, to stay truer to its original ideas and include a holistic understanding of ecosystem and human health and more sustainable (soil) management practices, organic regulations should include more environmental best practices in their process standards.

It is assumed that since the entry into force of the federal law "On Organic Agriculture" on January 1, 2020, this problem will be partially solved and significant changes will occur in the organic industry. However, the above analysis shows that the system of legal regulation in the area under study is still imperfect, so further work is needed, which will be associated not only with the improvement of legislation, but also with the creation of systems of state support and incentives, as well as information and methodological support. The country should create a comprehensive guarantee system for the quality of organic agricultural products, and producers should be motivated to perform their duties in good faith, since only in this case it is possible to improve the culture of healthy nutrition, the development of the domestic organic market and, as a result, to improve the level and quality of life of the population. 


\section{References}

1. J. Tressou, N.B. Abdallah, C. Planche, G. Dervilly-Pinel, P. Sans, E. Engel, I. Albert, Food Chem. Toxicol., 110, 251-261 (2017)

2. U. Kumar, A.K. Nayak, M. Shahid, V.V. Gupta, P. Panneerselvam, S. Mohanty, M. Kaviraj, A. Kumar, D. Chatterjee, B. Lal, P. Gautam, Agric. Ecosyst. Environ., 262, 65-75 (2018)

3. M.H. Ibrahim, H.Z.E. Jaafar, E. Karimi, A. Ghasemzadeh, Molecules, 18, 1097310988 (2013)

4. M. Głodowska, J. Krawczyk, Qual. Assur. SafCrop Foods, 9, 497-503 (2017)

5. P. Yanakittkul, C. Aungvaravong, Kasetsart. J. Soc. Sci., 1-8 (2017)

6. E. Ghazali, P.C. Soon, D.S. Mutum, B. Nguyen, J. Retailing Consum. Serv., 39, 154163 (2017)

7. J. Hwang, J.E. Chung, J. Retailing Consum. Serv., 47, 293-306 (2019)

8. S.H. Kim, Y.K. Seock, J. Retailing Consum. Serv., 51, 83-90 (2019)

9. G. Prakash, S. Choudhary, A. Kumar, J.A. Garza-Reyes, S.A.R. Khan, T.K. Panda, J. Retailing Consum. Serv., 50, 163-169 (2019)

10. B. Xie, L. Wang, H. Yang, Y. Wang, M. Zhang, Br. Food J., 117(3), 1105-1121 (2015)

11. L. Zollo, R. Filieri, R. Rialti, S. Yoon, J. Bus. Res., 117, 256-267 (2020)

12. Y.L. Chiew, J. Spångberg, A. Baky, P.A. Hansson, H. Jönsson, Resour. Conserv. Recycl., 95, 1-14 (2015)

13. P. Hennebert, Waste Manag., 74, 74-85 (2018)

14. N. Halberg, Can. J. Plant Sci.,92 (6), 981-996 (2012)

15. M.F. Bellamare, M. Çakir, H.H. Peterson, L. Novak, J. Rudi, Am. J. Agric. Econ., 99(5), 1148-1158 (2017) 